九州大学学術情報リポジトリ

Kyushu University Institutional Repository

\title{
Evaluation of a Multiple Linear Regression Model for the Prediction of Panicle Number in Rice
}

\author{
Yamauchi, Yusaku \\ Laboratory of Bioproduction and Environment Information Sciences, Course of Bioproduction \\ Environmental Sciences, Department of Agro-environmental Sciences, Graduate School of \\ Bioresource and Bioenvironmental Sciences, Kyushu University \\ Hirai, Yasumaru \\ Laboratory of Bioproduction and Environment Information Sciences, Course of Bioproduction \\ Environmental Sciences, Department of Agro-environmental Sciences, Graduate School of \\ Bioresource and Bioenvironmental Sciences, Kyushu University
}

Saruta, Ke isuke

YANMAR AGRICULTURAL MACHINERY MANUFACTURING CO., LTD.

\section{Yamakawa, Takeo}

Laboratory of Plant Nutrition, Department of Bioresource and Bioenvironmental Science, Faculty of Agriculture, Kyushu University

他

https://doi.org/10.5109/25200

出版情報: 九州大学大学院農学研究院紀要. 57 (2)，pp.421-426，2012-09-20. Faculty of Agriculture, Kyushu University

バージョン :

権利関係 : 


\title{
Evaluation of a Multiple Linear Regression Model for the Prediction of Panicle Number in Rice
}

\author{
Yusaku YAMAUCHI ${ }^{1}$, Yasumaru HIRAI*, Keisuke SARUTA ${ }^{2}$, Takeo YAMAKAWA ${ }^{3}$, \\ Eiji INOUE ${ }^{4}$, Takashi OKAYASU ${ }^{4}$ and Muneshi MITSUOKA ${ }^{4}$
}

\author{
Laboratory of Bioproduction Engineering, Division of Bioproduction Environmental Sciences, \\ Department of Agro-environmental Sciences, Faculty of Agriculture, \\ Kyushu University, Fukuoka 812-8581, Japan \\ (Received April 27, 2012 and accepted May 10, 2012)
}

\begin{abstract}
In Japan, rice production technology must be developed to meet stable yield and quality targets. This objective is important because of the demand for high quality rice by consumers, the necessity of enhancing Japan's international competitive power, and a declining trend in the production of first grade rice. To achieve stable yield and quality, it is important to control panicle number appropriately since it is a primary factor to determine rice yield and quality. In this study, a multiple linear regression model was built to predict panicle number, which can support the decision-making process of farmers in agricultural practice. Surveys of 33 paddy fields were conducted in the Fukuoka Prefecture in 2010-2011. Data regarding influential factors on panicle number, such as solar radiation, water temperature, and exchangeable ammo-nium $\left(\mathrm{eNH}_{4}\right)$ content in the soil, were collected and used for building the model as candidates of the explanatory variable. As the results, $\mathrm{eNH}_{4}$ content in the soil at the beginning of tillering stage and accumulated amount of daily solar radiation during the tillering stage were selected as explanatory variables. The adjusted coefficient of determination was 0.448 and RMSECV was 2.49. In the prediction model, $\mathrm{eNH}_{4}$ content in the soil at the beginning of the tillering stage was selected as an explanatory variable to represent inorganic nitrogen supply. In comparison, this variable does not reflect the inorganic nitrogen supplied throughout the tillering stage. This difference resulted in a large error in the field with organic fertilizer application, as the manner of inorganic nitrogen release is different to that of typical fields in the survey area that are subject-ed to chemical fertilizer application.
\end{abstract}

Keywords: multiple linear regression, panicle number, prediction model, rice

\section{INTRODUCTION}

In Japan, it is required to develop rice production technology that can achieve stable targets of yield and quality, given the high demands of consumers about rice quality, the necessity of enhancing our international competitive power, and a declining trend in the production of first grade rice (Ministry of Agricultaure, Forestry and Fisheries, 2011). Rice yield is determined by yield components such as panicle number, spikelet number, percentage of ripened grains, and grain weight (Kokubun, 2010). Among these components, panicle number is the most important because it significantly affects other yield components as well as rice quality. Panicle number is largely determined by tiller number, which is affected by various factors such as air tempera-

\footnotetext{
1 Laboratory of Bioproduction and Environment Information Sciences, Course of Bioproduction Environmental Sciences, Department of Agro-environmental Sciences, Graduate School of Bioresource and Bioenvironmental Sciences, Kyushu University

YANMAR AGRICULTURAL MACHINERY MANUFACTURING CO., LTD.

Laboratory of Plant Nutrition, Department of Bioresource and Bioenvironmental Science, Faculty of Agriculture, Kyushu University

${ }^{4}$ Laboratory of Bioproduction Engineering, Division of Bioproduction Environmental Sciences, Department of Agroenvironmental Sciences, Faculty of Agriculture, Kyushu University

* Corresponding author (E-mail: hirai@bpes.kyushu-u.ac.jp)
}

ture (Kobayashi et al., 1985), solar radiation (Shimizu et al., 1962; Kitagawa et al., 1988), water temperature (Honjo et al., 1968; Ueki, 1968), and soil nitrogen content (i.e., quantity of ammo-nium in the soil solution and exchangeable ammonium in the soil (Ando et al., 1988). Yet, the interaction of these factors is complicated; thus, tiller number has mainly been controlled on the basis of trial and error experiences of farmers. However, unstable rice yield and quality in recent years indicate limitation of agricultural practice when based on farmer experience. Hence, the development of a prediction model that expresses the relationship between tiller or panicle number and various influential factors is required to support the decision-making process of farmers in agricultural practice.

There has been a limited number of studies regarding prediction models on tiller or panicle number, with such studies being focused on factorial analysis. Tanifuji and Thokairin (1985) developed the successive prediction model for tiller and panicle numbers that focused on short-term forecasts. In this model, tiller and panicle numbers were predicted 10 to 20 days in advance by using plant length and tiller number at the time of prediction and daily mean temperature of ordinary year. This model may provide useful information to support decision-making for top-dressing; however, the model does not provide information about required basal fertilizer application, which is the most important practice to control tiller number. In addition, the explanatory variables included in the model were not sufficient to express 
the variation in panicle number, which occurs under different farm management styles or production environments in each field.

In this study, a multiple linear regression model was built to predict panicle number by using solar radiation, water temperature, and exchangeable ammonium $\left(\mathrm{eNH}_{4}\right)$ content in the soil as candidates of the explanatory variable. Furthermore, the prediction accuracy of the model was evaluated and ways to improve the model were examined.

\section{MATERIALS AND METHODS}

\section{Surveyed fields}

Field surveys were conducted in 2010-2011 in the Fukuoka Prefecture, Japan: at the experimental farm of Kyushu University in the Kasuya District (33 $36^{\circ} \mathrm{N}, 130^{\circ}$ $\left.27^{\prime} \mathrm{E}\right)$ during 2010; in the city of Fukuoka $\left(33^{\circ} 29^{\prime} \mathrm{N}\right.$, $130^{\circ} 21^{\prime} \mathrm{E}$ ) during 2010; and in the city of Itoshima $\left(33^{\circ}\right.$ $30^{\prime} \mathrm{N}-33^{\circ} 34^{\prime} \mathrm{N}, 130^{\circ} 08^{\prime} \mathrm{E}-130^{\circ} 15^{\prime} \mathrm{E}$ ) during $2010-2011$. Table 1 presents an outline of the paddy fields that were surveyed. In total, 33 fields were surveyed. The paddy fields in the Kasuya District (experimental farm of Kyushu University) were used as test plots for fertilizer and organic matter applications, with the area of each plot being 0.001 ha. The test was conducted under 7 different treatments with 3 replications. The 3 replications were averaged for each treatment. Thus, we assumed that three 0.001 ha fields were representative of 1 surveyed field of 0.003 ha subjected to the same treatment. Field size was approximately $0.1-0.2$ ha in Fukuoka and between 0.1 and 0.4 ha in Itoshima. All the paddy fields were located in an area of plains, except for 2 fields in Itoshima. The transplanting seasons were early July, mid-June to late June, and mid-June to early July for Kasuya, Fukuoka, and Itoshima, respectively. The 'Hinohikari' cultivar was grown in all the surveyed fields.

Table 1. Outline of the paddy fields surveyed

\begin{tabular}{rlrll}
\hline Year & Region & N. F. & Area(ha) & $\begin{array}{c}\text { Transplanting } \\
\text { date }\end{array}$ \\
\hline \multirow{2}{*}{2010} & Kasuya & 7 & 0.003 & 2 July \\
& Fukuoka & 2 & $0.1-0.2$ & 19, 23 June \\
& Itoshima & 9 & $0.1-0.4$ & 13-25 June \\
2011 & Itoshima & 15 & $0.1-0.4$ & 15 June-July 1 \\
\hline
\end{tabular}

N. F. represents number of fields.

\section{Manure and fertilizer application}

Table 2 outlines the application of manure and basal fertilizer to the surveyed fields. Information regarding fertilizer applications was collected by interviewing each farmer by telephone. The manner of application was divided into 8 categories: Winter manure-No basal fertilizer (W-N), Winter manure-Liquid fertilizer (W-L), Summer manure-No basal fertilizer $(\mathrm{S}-\mathrm{N})$, Summer manure-Chemical fertilizer (S-C), No manure-Liquid fertilizer $(\mathrm{N}-\mathrm{L})$, No manure-Chemical fertilizer $(\mathrm{N}-\mathrm{C})$,
No manure-Compound fertilizer (N-Co) and No manure -Organic fertilizer (N-O). At some test plots in Kasuya, liquid fertilizer or lime nitrogen was applied in winter to accelerate the maturity of rice straw, with a similar effect to manure being expected. Thus, we categorized liquid fertilizer and lime nitrogen applied in winter as manure. Manure was primary applied after harvesting (winter), or from 10 days to 1 month before basal fertilization (summer). Basal fertilizer was applied from 1 to 16 days

Table 2. Outline of the application of manure and basal fertilizer

\begin{tabular}{cccc}
\hline $\begin{array}{c}\text { Application } \\
\text { Type }\end{array}$ & N. F & $\begin{array}{c}\text { Manure } \\
\left(\mathrm{kg} \mathrm{N} \mathrm{ha}^{2)}\right)\end{array}$ & $\begin{array}{c}\text { Basal } \\
\text { fertilizer } \\
\left(\mathrm{kg} \mathrm{N} \mathrm{ha}^{-1}\right)\end{array}$ \\
\hline W-N & 3 & $61.5^{4)}$ & 0 \\
W-L & 1 & 61.5 & 50 \\
S-N & 3 & $40^{5)}$ & 0 \\
S-C & 3 & 40 & $12-32$ \\
N-L & 2 & 0 & 50 \\
N-C & 16 & 0 & $36-60$ \\
N-Co & 3 & 0 & $40-42$ \\
N-O & 2 & 0 & $72-77$ \\
\hline
\end{tabular}

1) W-N, W-L, S-N, S-C, N-L, N-C, N-Co and N-O represent Winter manure-No basal fertilizer, Winter manure-Liquid fertilizer, Summer manure-No basal fertilizer, Summer manure-Chemical fertilizer, No manure-Liquid fertilizer, No manure-Chemical fertilizer, No manure-Compound fertilizer and No manure-Organic fertilizer, respectively. ${ }^{2)}$ N. F. represents number of fields. ${ }^{3)}$ The amount of application is shown in total nitrogen $\left(\mathrm{kg} \mathrm{N} \mathrm{ha}^{-1}\right)$. ${ }^{4)}$ The amount in one field was not obtained. ${ }^{5)}$ The amounts in two fields were not obtained.

before transplanting.

\section{Meteorological conditions and water temperature}

Air temperature and solar radiation were measured at representative points in each surveyed region by using a meteorology monitoring apparatus (HOBO Weather Stations, Onset Computer Cooperation, Bourne, MA, USA). Water temperature was measured at approximately the center of each paddy field by using a thermo recorder (RTR-52, T\&D Corporation, Nagano, Japan) and a wireless data collector (RTR-57U, T\&D Corporation, Nagano, Japan). Each data was logged at 10-min intervals during the period of rice growth.

\section{Survey of rice growth}

In 2010, growth indicators, such as plant length and tiller number, were monitored in 2 plots for 5 continuous hills in the direction of a planting row at $1-$ to 2 -week intervals during the rice growth period (i.e., 10 hills in total). The plots were located in a diagonal direction across the field and were not close to a water inlet or levee. In 2011, plant length and tiller number were monitored in 2 plots (diagonal plots across the field) for 2 and 10 continuous hills in the direction of a planting row (i.e., 4 and 20 hills in total, respectively). The number and location of the hills that were monitored were determined on the basis of the reports by Kusuda (1990a, 
1990b, 1992) as well as the required labor effort in the fields during the surveys. The growth indicators in each field were calculated as the average values of all the monitored hills.

\section{Measurements of exchangeable ammonium in the soil}

The rice rhizosphere soil in each flooded field was sampled (depth, 0 to $15 \mathrm{~cm}$ ) at 3 locations where plant length and tiller number were close to the average values calculated in the growth survey. The soil was sampled using a cylindrical tube of $3 \mathrm{~cm}$ in diameter and $30 \mathrm{~cm}$ in length. Sampling was conducted at 3 growth stages of rice: beginning of tillering, active tillering, and maximum tiller-number stage. We defined the 3 growth stages as 15, 25, and 40 days after transplanting, respectively. The soil samples were freeze-dried for approximately $48 \mathrm{~h}$, and were then ground and passed through a 2-mm sieve. Exchangeable ammonium $\left(\mathrm{eNH}_{4}\right)$ content in soil of the samples was measured using the following procedure. First, $10 \mathrm{~g}$ of dry soil was placed in a glass bottle. The bottle was shaken for $1 \mathrm{~h}$, after adding $100 \mathrm{ml}$ of $0.5 \mathrm{M}$ potassium sulfate. Then, soil extract was obtained by filtering the solution. The $\mathrm{eNH}_{4}$ content in the soil was then measured once for each soil extract by using the indophenol method (Cataldo et al., 1974). Absorbance at $625 \mathrm{~nm}$ was determined using a spectrophotometer (V-630, JASCO, Tokyo, Japan) with a rapid sampler (NQF-720, JASCO, Tokyo, Japan). The average value of 3 samples in each field was calculated.

\section{Multiple linear regression model for the predic- tion of panicle number}

The multiple linear regression model was built by assuming the following linear relationship between the panicle number and explanatory variables.

$$
\hat{y}=\hat{\boldsymbol{\beta}}^{T} \boldsymbol{x}
$$

where $\boldsymbol{x}=\left(1, x_{1}, x_{2}, \cdots, x_{p}\right)$ is the vector of explanatory variables, including 1 for intercept $\beta_{0} ; \hat{y}$ is the prediction value of panicle number per hill; $\hat{\beta}^{T}=\left(\hat{\beta}_{0}, \hat{\beta}_{1}, \hat{\beta}_{2}, \cdots, \hat{\beta}_{p}\right)$ is the transverse vector of the regression coefficient estimated by the least squares method.

Table 3 shows candidate explanatory variables that were used to build the multiple linear regression model. The candidate variables were determined on the basis of the reports of previous studies regarding the correlation between tiller number and influential factors, because panicle number is closely correlated with tiller number. Ando et al. (1988) reported that tiller number is affected by $\mathrm{eNH}_{4}$ content in the soil rather than ammonium in the soil solution under high temperature conditions $\left(25^{\circ} \mathrm{C}\right.$, daytime; $15^{\circ} \mathrm{C}$, night-time). Air temperature conditions in the surveyed paddy fields fell in the high temperature conditions. The $\mathrm{eNH}_{4}$ content in the soil at the beginning of tillering stage and at the active tillering stage were determined by linear interpolation on the basis of measurement $\mathrm{eNH}_{4}$ content collected during the 3 growth stages. The $\mathrm{eNH}_{4}$ content in the soil is an indicator of inorganic nitrogen supply and may be related to basal fertilizer application in future research. Honjo et al. (1968) reported that tiller number was positively correlated with daily mean water temperature. Kitagawa et al. (1988) reported that there are positive correlations between maximum tiller number and daily solar radiation during the 20-day period before the maximum tillernumber stage $(r=0.702)$ and between the percentage of productive tiller and daily solar radiation during the 20-day period after the maximum tiller-number stage ( $r=0.72)$. Further, Shimizu et al. (1962) reported that tiller number is positively correlated with daily solar radiation during the 20 -day period after rooting. In this study, the period from 10 days after transplanting to 30 days before heading was defined as the tillering period. The maximum tiller-number stage was identified by using spline interpolation, which was based on the tiller number monitored throughout the growth period. This information was used to calculate the accumulated amount of daily solar radiation during the 20-day period after this stage. Furthermore, Kakizaki (1987) reported that temperature at the base of rice culm, which is close to apical meristem, significantly affects emergence and growth of tiller. The base of rice culm during tillering stage is in water under flooded condition. Thus, we selected indicators regarding water temperature rather than air temperature as candidate explanatory variables.

A stepwise method was applied to select explanatory variables in the multiple linear regression model. The value $F_{0}$ shown in equation (2) was used as a criterion for variable selection (Haga and Hashimoto, 1980). The value $F_{0}$, which follows the $F$-distribution, is the ratio of change in the regression sum of squares $D_{j}$ in adding or reducing an explanatory variable $x_{j}$ to residual variance $V_{\mathrm{e}}$.

Table 3. Candidate explanatory variables used for building a multiple linear regression model

\begin{tabular}{cl}
\hline No. & \multicolumn{1}{c}{ Variables } \\
\hline 1 & $\mathrm{eNH}_{4}$ content in the soil at the beginning of the tillering stage \\
2 & $\mathrm{eNH}_{4}$ content in the soil at the active tillering stage \\
3 & Daily mean water temperature during the tillering stage \\
4 & Accumulated amount of daily mean water temperature during the tillering stage \\
5 & Daily solar radiation during the tillering stage \\
6 & Accumulated amount of daily solar radiation during 20-day period after rooting \\
7 & Accumulated amount of daily solar radiation during the tillering stage \\
8 & Accumulated amount of daily solar radiation during 20-day period after the maximum tiller-number stage
\end{tabular}




$$
F_{0}=D_{j} / V_{\mathrm{e}}
$$

Furthermore, $V_{\mathrm{e}}$ is calculated using the following equation:

$$
V_{\mathrm{e}}=S_{\mathrm{e}} /(n-k-1)
$$

where $k$ is the number of variables included in the regression model, $n$ is the number of datasets, and $S_{\mathrm{e}}$ is the residual sum of squares. An explanatory variable was selected under the condition that $F_{0}$ is larger than the $F$ value with 1 (numerator) and $n-k-1$ (denominator) degrees of freedom at the $5 \%$ significance level.

\section{Evaluation of multiple linear regression model}

The prediction accuracy of the multiple linear regression model was evaluated by using root mean square error in leave-one-out cross-validation (RMSECV) shown in equation (4).

$$
R M S E C V=\sqrt{\frac{1}{n} \sum_{i=1}^{n}\left\{y_{i}-\hat{y}\left(\boldsymbol{x}_{i} ; \hat{\boldsymbol{\beta}}^{(-i)}\right)\right\}^{2}}
$$

where $i$ is an index representing data number; $n$ is the total number of datasets, $\boldsymbol{x}_{i}$ is $i$ th data on explanatory variables; $y_{i}$ is the measured panicle number per hill; $\hat{y}\left(\boldsymbol{x}_{i} ; \hat{\boldsymbol{\beta}}^{(-i)}\right)$ is the panicle number per hill predicted by substituting $\boldsymbol{x}_{i}$ into the multiple linear regression model built using all data, except for the ith data; $\hat{\boldsymbol{\beta}}^{(-i)}$ is a regression coefficient vector estimated using all data, except for the ith data. All computations in this study were performed using macros written in Microsoft Excel.

\section{RESULTS}

Table 4 shows the coefficients of multiple correlation, determination, and regression. The $\mathrm{eNH}_{4}$ content in the soil at the beginning of tillering stage and accumulated amount of daily solar radiation during the tillering stage were selected as explanatory variables to predict panicle number per hill. Standardized partial regression coefficients of the 2 selected variables had approximately the same positive values. This result indicates that the 2 explanatory variables had a similar contribution to the change in panicle number. The adjusted coefficient of determination was 0.448 and RMSECV was 2.49. Figure 1 shows the relationship between measured panicle number and predicted values. Two paddy fields were confirmed to show relatively large errors, i.e., 4.8 and
6.8 hill $^{-1}$.

\section{DISCUSSION}

The $\mathrm{eNH}_{4}$ content in the soil at the beginning of the tillering stage and the accumulated amount of daily solar radiation during the tillering stage were selected as explanatory variables in the prediction model. According to Ando et al. (1988), tiller number is mainly affected by $\mathrm{eNH}_{4}$ content in the soil under high air temperature conditions $\left(25^{\circ} \mathrm{C}\right.$, daytime; $15^{\circ} \mathrm{C}$, night-time). Air temperature in the surveyed paddy fields fell within this stated high temperature condition. Thus, the selection of $\mathrm{eNH}_{4}$ content in the soil was assumed to be valid. The reason that the value at the beginning of the tillering stage was selected was because $\mathrm{eNH}_{4}$ content in the soil decreased linearly from the beginning of the tillering stage to the maximum tiller number stage in most surveyed fields where chemical fertilizer was applied as the basal fertilizer. Hence, differences in $\mathrm{eNH}_{4}$ content among surveyed fields could only be represented by using values at the beginning of the tillering stage. The selection of the accumulated amount of daily solar radiation during the tillering stage was validated by a positive correlation $(r=0.72)$ between the maximum tiller number and daily solar radiation during the 20-day period before the maximum tiller-number stage, as reported by Kitagawa et al.

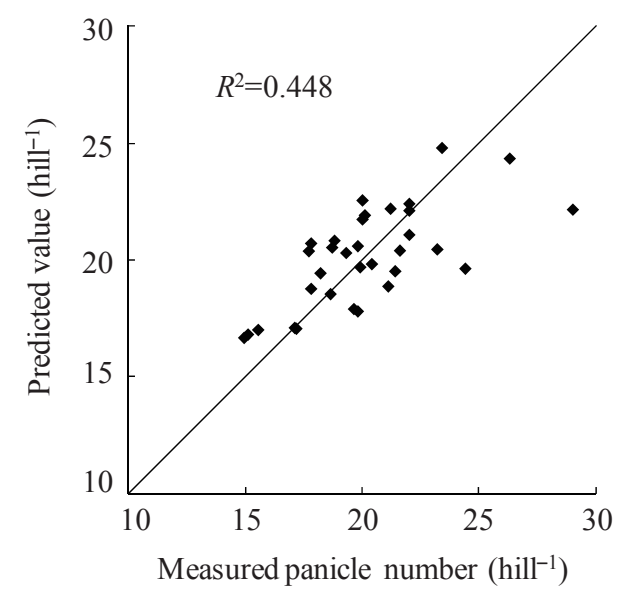

Fig. 1. Relationship between measured panicle number and predicted values.

Solid line in the figure indicates that measured values

\begin{tabular}{|c|c|c|}
\hline Degrees of freedom adjustment & Multiple correlation coefficient & Coefficient of determination \\
\hline Not adjusted (Ordinary) & 0.695 & 0.483 \\
\hline Adjusted & 0.670 & 0.448 \\
\hline Explanatory variables selected & Partial regression coefficient & Standardized partial regression coefficient \\
\hline $\begin{array}{l}\mathrm{eNH}_{4} \text { content in the soil at the beginning } \\
\text { of the tillering stage }\end{array}$ & 1.074 & 0.510 \\
\hline $\begin{array}{l}\text { Accumulated amount of daily solar } \\
\text { radiation during the tillering stage }\end{array}$ & 0.028 & 0.478 \\
\hline
\end{tabular}
equal to predicted ones.

Table 4. Coefficients of multiple correlation, determination, and regression 
Table 5. Values of the explanatory variables, measured and predicted panicle number, and error for 2 fields with large prediction errors

\begin{tabular}{cccccc}
\hline Field & $\begin{array}{c}\mathrm{eNH}_{4} \text { in soil } \\
\left(\mathrm{mg} \mathrm{100} \mathrm{g}^{-1}\right)\end{array}$ & $\begin{array}{c}\text { Accumulated solar } \\
\text { radiation }(\mathrm{MJ})\end{array}$ & $\begin{array}{c}\text { Measured } \\
\left(\text { hill }^{-1}\right)\end{array}$ & $\begin{array}{c}\text { Predicted } \\
\left(\text { hill }^{-1}\right)\end{array}$ & $\begin{array}{c}\text { Error } \\
\left(\text { hill }^{-1}\right)\end{array}$ \\
\hline A & 3.52 & 480 & 29.0 & 22.2 & 6.8 \\
B & 1.73 & 458 & 24.4 & 19.6 & 4.8 \\
$\begin{array}{c}\text { Average on all } \\
\text { fields }\end{array}$ & 2.48 & 446 & 20.1 & 20.1 & 1.7 \\
\hline
\end{tabular}

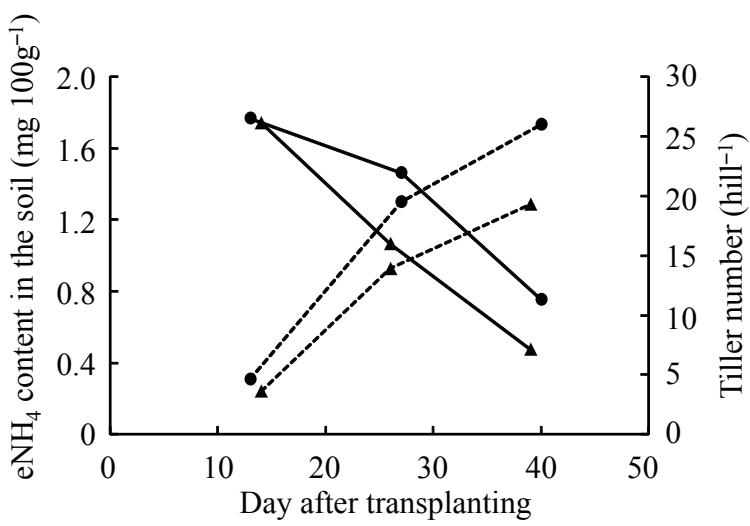

Fig. 2. Temporal changes in tiller number and $\mathrm{eNH}_{4}$ content in the soil for fields B and C.

Solid circle $(\mathbf{)}$ ) represents field $\mathrm{B}$, solid triangle $(\boldsymbol{A})$ represents field $\mathrm{C}$, solid line represents eNH4 content in the soil, dotted line represents tiller number.

(1988). Although this correlation was not for panicle number, maximum tiller number may be used as an indicator of panicle number because of the strong positive correlation $(r=0.90)$ obtained between these 2 parameters in the current survey.

Table 5 shows the values of the explanatory variables, measured and predicted panicle number, and the error for 2 fields with large prediction errors. For field A, the predicted value was slightly higher than the average of all the fields, whereas the measured value was significantly higher than the average value; this resulted in a large error of $6.8 \mathrm{hill}^{-1}$. Because slow-release organic fertilizer was applied in field A, a slow supply of inorganic nitrogen across a long period was assumed as the reason for this large error. However, the change in $\mathrm{eNH}_{4}$ content in the soil during the tillering period did not differ significantly from that in typical fields where chemical fertilizer was applied; thus, the reason for this reference was not identified from the data obtained in this study. For field B, the predicted value was lower than the measured value because $\mathrm{eNH}_{4}$ content in the soil at the beginning of tillering stage was low. Because poultry manure was applied in field B, a slow supply of inorganic nitrogen over a long period was inferred as the reason for the large measured value. Figure 2 shows temporal changes in tiller number and $\mathrm{eNH}_{4}$ content in the soil for fields B and C. Chemical fertilizer was applied in field C, with $\mathrm{eNH}_{4}$ content in the soil being equivalent to that in filed $\mathrm{B}$ at the beginning of the tillering stage. The $\mathrm{eNH}_{4}$ content in the soil decreased slower in field B than in field
C. As a result, the tiller number of field B increased more rapidly than that in field $\mathrm{C}$. In the prediction model built in this study, $\mathrm{eNH}_{4}$ content in the soil at the beginning of the tillering stage was selected as an explanatory variable to represent inorganic nitrogen supply. In comparison, this variable does not reflect the inorganic nitrogen supplied throughout the tillering stage. This difference resulted in a large error in the field with organic fertilizer application, as the manner of inorganic nitrogen release is different to that of typical fields in the survey area that are subjected to chemical fertilizer application. In addition, we examined whether sparse planting density in field B contributed to the error. The planting density was 15.8 hills $\mathrm{m}^{-2}$ in field $\mathrm{B}$, while the average density was 17.6 hills $\mathrm{m}^{-2}$ in the other surveyed fields. Hirano et al. (1997) reported that the number of productive tillers per hill was higher at sparse planting densities than standard planting density. This outcome arises because an increase in the number of secondary tillers and decrease in non-productive tillers are caused by high photosynthetic ability under increased relative light intensity in plant communities.

Finally, it is necessary to increase the prediction accuracy based on RMSECV of 2.49 and ad-justed coefficient of determination of 0.448 . This study indicates that the supply of inorganic nitrogen throughout the tillering stage and planting density are variables that should be considered toward improving the model in the future.

\section{ACKNOWLEDGEMENTS}

The authors thank farmers of Itoshima rice production management association and JA Itoshima staff for their helpful support for our field survey.

\section{REFERENCES}

Ando, Y., K. Adachi, M. Minami and N. Nishida 1988 Effect of ammonium nitrogen on the tillering-habit of rice plant. Jpn. J. Crop Sci., 57(4): 678-684 (In Japanese with English abstract)

Cataldo, D. A., L. E. Schrader and V. L. Youngs 1974 Analysis by digestion and colorimetric assay of total nitrogen in plant tissues high in nitrate. Crop Science, 14: 854-856

Haga, T. and S. Hashimoto 1980 Regression analysis and principal component analysis. Union of Japanese Scientists and Engineers, Tokyo (Japan), pp. 2-84 (In Japanese)

Hirano, M., K. Yamasaki, T. T. Hop, E. Kuroda and T. Murata 1997 Effects of combined practice of nitrogen application regime with sparse planting on the growth and yield of rice. Jpn. J. Crop Sci., 66(4): 551-558 (In Japanese with English abstract) 
Honjo, K., H. Kashibuchi, M. Hirano and T. Kaneko 1968 Studies on the effects of the alteration of water temperature in the daytime and the nighttime upon the growth of rice plants at tillering stage. Rep. Tohoku Br. Crop Sci. Soc. Japan, 10: 3-4 (in Japanese)

Kakizaki, Y. 1987 Studies on tillering of rice plants: Temperature effects of tillering in case of culm-bases treated with $15^{\circ} \mathrm{C}$ and $35^{\circ} \mathrm{C}$ water. Rep. Tohoku Br. Crop Sci. Soc. Japan, 30: 12-15 (in Japanese with English title)

Kitagawa, H., O. Matsumura, K. Shimotsubo and M. Hatae 1988 Climatic influence on yield and yield components of lowland rice in the warmer part of Japan: I. Spikelets growth in relation to temperature and solar radiation. Rep. Kyushu Br. Crop Sci. Soc., 55: 49-52 (in Japanese with English title)

Kobayashi, Y., S. Abe and K. Okabe 1985 Forecast of the growth and yield of rice plant: I. Forecast of ears. Rep. Tohoku Br. Crop Sci. Soc. Japan, 28: 45-46 (in Japanese with English title)

Kokubun, M. 2010 Food crop. Yokendo, Tokyo (Japan), p. 67 (In Japanese)

Kusuda, O. 1990a A basic study on field experiment and investigation methods in rice plant: I. Coefficient of variation and standard sample size in the survey of quantitative characters. Jpn. J. Crop Sci., 59(1): 80-88 (in Japanese with English abstract)

Kusuda, O. 1990b A basic study on field experiment and investigation methods in rice plant: $\mathbb{I}$. Coefficient of variation and standard sample size in the survey of quantitative characters of mechanically transplanted rice. Jpn. J. Crop Sci., $\mathbf{5 9 ( 4 ) : ~}$ 721-726 (in Japanese with English abstract)

Kusuda, O. 1992 A basic study on field experiment and investigation methods in rice plant: III. Precision of some sampling methods in sample survey of quantitative characters Jpn. $J$. Crop Sci., 61(3): 412-418 (in Japanese with English abstract)

Ministry of Agriculture, Forestry and Fisheries 2011 Change in first grade rice and inspection results of non-glutinous brown rice in fiscal year 2010 (as of January 31st in 2011). In http:// www.maff.go.jp/j/study/suito_sakugara/h2203/pdf/ref_ data2-4.pdf, Ministry of Agriculture, Forestry and Fisheries, Tokyo (In Japanese)

Shimizu, T., T. Sekiguchi, H. Morita and M. Susaki 1962 Studies on yield-forecast in main crops: VIII: Effect of light intensity on the tillering of rice plant. Jpn. J. Crop Sci., 31(2): 141144 (in Japanese with English summary)

Tanifuji, Y. and H. Tokairin 1985 Modeling and application of the successive prediction of paddy rice growth. Bull. Yamagata Agric. Res. Cent., 19: 1-22 (In Japanese with English abstract)

Ueki, K. 1968 Effects of a decline in water temperature under continuous irrigation during the tillering stage on panicle number in rice: Difference in the effects under different cultivars and amounts of fertilizer application. Rep. Kyushu Br. Crop Sci. Soc., 31: 37-39 (in Japanese) 